\title{
a interpretación del patrimonio natural y cultural: todo un camino por recorrer
}

Jorge Morales Miranda

Coordinador de la Asociación para la Interpretación del Patrimonio (España), y miembro del Panel Internacional de la Asociación Heritage Interpretation International
Abordar un artículo acerca de la interpretación del patrimonio para el prestigioso Boletín PH, se me presenta como un alto listón que debo superar desde la perspectiva de mi modesto campo de trabajo, aquí, en un medio acostumbrado a disertaciones de gran nivel. No obstante, mi exposición será simple y descriptiva de lo que considero como la joven realidad de la interpretación; así que invito a los estimados lectores a continuar con estas páginas.

He leído algunos Boletines PH y el número de Cuadernos del IAPH dedicado a la Difusión del Patrimonio Histórico, y he comprobado el enorme interés que despierta este aspecto de la gestión, el antepenúltimo eslabón de la cadena de acciones para "presentar" el patrimonio al público. También he podido comprobar que, pese a los esfuerzos, aún cuesta llegar a una homologación de los términos relativos a la difusión del patrimonio. Cada uno los entiende y utiliza como mejor cree desde su arena: desde la museología a la extensión, desde la educación ambiental a la práctica de guiar en turismo. Y, por supuesto, distinta es la terminología según se trabaje en (o para) el patrimonio natural o el histórico.

Intentaré esbozar algunos conceptos relacionados con la interpretación, a secas. Trataré, también, de no dejarme intimidar por una nomenclatura que, a veces, puede resultar un poco rara para aquellos que provenimos de un ámbito diferente. Confieso que hace un poco más de un año que oí por primera vez el término "puesta en valor". Así mismo, también es probable que muchos no hayan oído nunca los conceptos "planificación interpretativa" o "interpretación temática".

\section{La interpretación está bien definida, pero en España no se aplica}

El término interpretación fue incorporado en España en el último tercio del siglo $X X$; provino, sin duda, del ámbito anglosajón... de los Estados Unidos, para ser exactos. En aquel país nació a finales del siglo XIX, después de la declaración de los primeros parques nacionales. Allí la interpretación obtuvo ma- yoría de edad tras la publicación y divulgación de la obra de Freeman Tilden "Interpreting Our Heritage", en 1957. De todos modos, la interpretación es un acto de transferencia cultural que puede ser tan antiguo como la humanidad, aunque se le haya definido y denominado sólo hace unos cien años.

Esta disciplina llegó a España con el apellido de "ambiental", debido a que en la década de los sesenta en los Estados Unidos se le comenzó a denominar environmental interpretation. Aquí se intentó "aplicar" a los parques nacionales españoles, o al menos se utilizó el término, sin ningún éxito, dado que la interpretación en los parques españoles deja mucho que desear, si acaso existe en la actualidad.

Desde mediados de los ochenta, y en el ámbito internacional, se comienza a hacer referencia a la disciplina como interpretación del patrimonio, una denominación menos excluyente que la hasta entonces utilizada, interpretación ambiental. Esta denominación se consolida en el Primer Congreso Mundial de Interpretación del Patrimonio, en Banff, Canadá, en 1985. El apelativo "del patrimonio" es más amplio que el de "ambiental", pues abarca también a aquellos aspectos, manifestaciones o fenómenos relacionados con el medio natural.

Hemos de reconocer que la palabra patrimonio habitualmente se asocia más a cuestiones relacionadas con lo histórico, lo cultural o lo artístico, al menos así la utilizan algunos técnicos de la Administración y profesionales de la antropología, la arquitectura o la historia. Y cuando se refieren a patrimonio no están pensando precisamente en pinsapos, buitres leonados o en reservas de genes, sino, más probablemente, en catedrales y conjuntos arqueológicos. Bueno, es una deformación profesional comprensible, creo que a todos nos pasa. Trabajamos para el patrimonio tanto unos como otros.

Pero no voy a hablar de patrimonio, sino de interpretación, como dije al principio: a secas. Esta disciplina ha sido definida en numerosas ocasiones por distintos organismos. Presentaré algunas de las definiciones que, a mi juicio, son las más clarificadoras. 
"La interpretación del patrimonio es el arte de revelar in situ el significado del legado natural, cultural o histórico, al público que visita esos lugares en su tiempo de ocio".

\section{Freeman Tilden (1957):}

"La interpretación es una actividad educativa que pretende revelar significados e interrelaciones a través del uso de objetos originales, por un contacto directo con el recurso o por medios ilustrativos, no limitándose a dar una mera información de los hechos".

(El empleo del binomio "actividad educativa" se prestó a muchas confusiones, llegándose incluso a polemizar al respecto durante décadas. El mismo Freeman Tilden declaró más tarde, poco antes de morir, que si tuviese que revisar de nuevo su libro, comenzaría su definición por: "es una actividad recreativa...")

\section{Don Aldridge (1973):}

"La interpretación es el arte de explicar el lugar del hombre en su medio, con el fin de incrementar la conciencia del visitante acerca de la importancia de esa interacción, y despertar en él un deseo de contribuir a la conservación del ambiente".

(Aldridge es considerado el pionero de la interpretación en el Reino Unido y en el resto de Europa)

\section{Yorke Edwards (1976):}

"La interpretación posee cuatro características que hacen de ella una disciplina especial: es comunicación atractiva, ofrece una información concisa, es entregada en presencia del objeto en cuestión y su objetivo es la revelación de un significado".

(Definición muy contundente y nada retórica, adoptada por muchos profesionales de Canadá)

\section{Bob Peart (1977):}

"La interpretación es un proceso de comunicación diseñado para revelar al público significados e interrelaciones de nuestro patrimonio natural y cultural, a través de su participación en experiencias de primera mano con un objeto, artefacto, paisaje o sitio".

\section{Paul Risk (1982):}

"La interpretación, sea a través de charlas o por otros medios, es exactamente lo que la palabra quiere decir: la traducción del lenguaje técnico y a menudo complejo del ambiente, a una forma no técnica -sin por ello perder su significado y precisión-, con el fin de crear en el visitante una sensibilidad, conciencia, entendimiento, entusiasmo y compromiso. (N. del A: seguramente la frase acaba mejor "...hacia el recurso que es interpretado")

\section{Rideout-Civitarese, Legg y Zuefle (1997):}

"La interpretación es una actividad de comunicación diseñada para mejorar la calidad de la experiencia recreativa del visitante, y para inspirar, de una forma agradable, un mayor aprecio por el recurso".

Modestamente, también planteo una definición que espera su debate en el seno de la Asociación (Española) para la Interpretación del Patrimonio. Es coautor mi colega Francisco Guerra, fundador también de la Asociación:

"La interpretación del patrimonio es el arte de revelar in situ el significado del legado natural, cultural o histórico, al público que visita esos lugares en su tiempo de ocio".

\section{Es un servicio público de inestimable valor}

En España, en Andalucía, he topado un par de veces con el siguiente concepto:

"La interpretación es un método para la presentación, comunicación y explotación del patrimonio".

Me parece una descripción bastante desafortunada y reduccionista. Pienso que se debería tener muchísimo cuidado al asociar el concepto de interpretación al de explotación. Desde luego, podemos considerar que hay una explotación asimilable al término aprovechamiento, que da cabida a la noción de 
uso/beneficio, sea éste intelectual, social o económico, todos lícitos dentro de los márgenes que imponga la ética profesional (o las leyes). Pero la pura y dura palabra "explotación" necesita de matices, para no generalizar la idea que la interpretación es un instrumento que permite vender o comerciar con el patrimonio que es interpretado. Quizá sea mejor evitar esa palabra en las definiciones o descripciones de interpretación

Considero que la interpretación es -o debería serun servicio público: la culminación de la puesta en valor de unos rasgos o fenómenos del patrimonio natural e histórico, para su uso y disfrute por todo tipo de público que se encuentre en su tiempo de ocio. Y todo tipo de público incluye a los discapacitados físicos, sensoriales y psíquicos; que no se olvide esto para el diseño de los equipamientos y los programas.

Pienso, también, que el público tiene derecho a disfrutar del patrimonio, derecho a sentirlo, a comprenderlo y, como consecuencia, a apreciarlo y contribuir a su conservación. Y las instituciones públicas tienen el deber de facilitar ese acercamiento, en lo posible de manera gratuita e igualitaria.

Presumiblemente, para un concesionario (sector privado) la interpretación no será rentable por sí sola, si pensamos en que cobrará unas tasas asequibles a todo tipo de público. Para obtener beneficios directos de la interpretación, ese concesionario tendría que mantener unos precios prohibitivos para la gran mayoría de los ciudadanos -los pretendidos como auténticos destinatarios de la interpretación-, relegándola a un círculo elitista, y perpetuando la noción de que la cultura y el disfrute de la naturaleza son un coto privado para los pudientes. Enseguida retomo esta cuestión, ya que me extenderé algo en este curioso asunto de los beneficios de la interpretación del patrimonio natural y cultural.

\section{La interpretación es una buena inversión}

Las instituciones que realicen interpretación estarán haciendo, al mismo tiempo, una inversión, rentable a corto y a largo plazo. La rentabilidad inmediata vendrá dada en una mejora de la gestión: mejor utilización del espacio por parte del visitante y, por consiguiente, menor impacto en el recurso/patrimonio; menos vandalismo; mayor concienciación y mejores actitudes durante la estancia en el sitio y, probablemente, unos comportamientos acordes con el lugar que se visita. Este enfoque de la interpretación como instrumento de gestión no es nada nuevo, y está comprobado que bien ejecutada incluso puede ayudar a ahorrar dinero (en mantenimiento y en reparaciones, por ejemplo).

La rentabilidad a corto plazo de todo aquello que gira en torno a la interpretación también la podemos evidenciar en la gestión de algunos concesionarios que concienzudamente realizan su labor, aplicando criterios profesionales para la comunicación con el público, y cumpliendo lo estipulado -a ese respectoen el contrato y las prescripciones técnicas. Sin embargo, su producto consiste en una amplia gama de servicios -incluido el asesoramiento técnico a la Administración-, donde el concepto de programa interpretativo sólo es una pequeña parcela de toda la actividad económica, muchas veces generadora de gastos más que de ingresos (vehículos, materiales, sueldos de guías y monitores, seguros, etc.).

Desde luego, la pura interpretación no es rentable económicamente de manera directa, como no lo es la sanidad ni el sistema educativo públicos. Puede ser un factor de impulso económico para una zona merced a determinados servicios colaterales, tales como cafeterías, venta de recuerdos y transporte; y, en general, constituye un aliciente para el comercio local si va aparejada a un incremento en la demanda turística. Pero no perdamos de vista que estamos refiriéndonos a la interpretación del patrimonio, porque algunos espectáculos pretenciosos y mediocres también pueden ser un factor de dinamismo económico.

Consideremos, además, que esta disciplina da dividendos a numerosos profesionales que trabajan en sus distintos frentes. Yo mismo intento vivir de ella.

También es rentabilísima para ciertas empresas que se promocionan como las mejores productoras de montajes interpretativos, o como las mejores instaladoras del "mobiliario" de los mal llamados centros de interpretación. En efecto, estos montajes pueden deslumbrar en el momento de su inauguración: por la espectacularidad y los efectos especiales, o por lo llamativo de unos paneles con fotos y textos redactados por especialistas en los diversos contenidos... Eso no es interpretación.

La rentabilidad a largo plazo vendrá dada por una mejora de la imagen pública de la institución; así está comprobado en el caso de los parques nacionales norteamericanos. ¿Por qué no hemos de sentir deseos de felicitar y agradecer a una red de parques o a la administración de conjuntos históricos, si en nuestra visita se nos ha atendido bien? Si se nos trata con sensibilidad y deferencia; si se alude a nuestra personalidad; si se cuenta con nuestra inteligencia para construir la interpretación y se nos presenta la esencia del sitio de forma amena, precisa, breve y honesta; y si el guía o los cartelitos nos invitan a pensar y a sorprendernos ipor qué no vamos a pensar "qué bien lo están haciendo los de la Junta"?

Por el contrario, si visitamos un parque y no nos orientan (dónde estamos, cómo podemos aprovechar mejor nuestro tiempo); si los guías o informadores nos atienden como si nos estuviesen haciendo un favor (si acaso hay personal); si los textos de las exhibiciones son ininteligibles (¡tienen más de cien palabras!), la letra es muy pequeña, el contraste de colores de texto y fondo es insoportable; y si al final nos vamos con una ensalada en la cabeza... ipor qué no hemos de pensar que esa institución está siendo 
irresponsable con nuestros impuestos y, en algunos casos, derrochando dinero público en costosas instalaciones y medios "interactivos" (apretar botones) mal mantenidos e ineficaces?

Tampoco nos engañemos, la mayoría de los visitantes pueden expresar un comentario como éste: "¡Qué bonito, qué maquinitas tan entretenidas!" Pero su acercamiento al patrimonio sólo habrá sido ver fotos, revolcarse por una duna o trepar por el muro de un castillo; y ése puede que sea todo el significado que se les haya revelado.

La rentabilidad a largo plazo de la interpretación también se fundamenta en una ciudadanía que comprende y aprecia su patrimonio. No toda la ciudadanía, evidentemente, pero un sector importante de ella puede entrar en contacto con programas o servicios interpretativos mientras disfruta de su ocio en determinados lugares.

Ante esto quisiera hacer notar que la interpretación no es para los expertos o para los ya sensibilizados. El naturalista o el conocedor de la historia/cultura no necesita interpretación; probablemente no se apunte a actividades interpretativas. La interpretación puede llegar a una inmensa mayoría, gente común y corriente, que ve telenovelas en lugar de documentales (en televisión los ponen a la misma hora); en cierta medida es para los domingueros y paseantes, para turistas normalitos, para los que salen al campo a dar un paseo o visitan unas ruinas romanas durante su estancia en la playa o sus vacaciones en el interior. $Y$ para ellos (para mí, para mis hermanas, mis cuñados, mi padre), la clave está en el lenguaje que se utilice, en el dominio de unas técnicas, pero también en el arte de conseguir seducir y llegar al corazón además de a la razón de las personas.

\section{La interpretación aplica ciertas técnicas, pero también depende del arte de los que la realizan}

Hasta el día de hoy es muy difícil encontrar verdaderos ejemplos de interpretación en España. Son la excepción algunos programas conducidos por guías (de turismo, de parques nacionales y naturales, y de sitios históricos y arqueológicos). En estas actividades es la manera de hacer y el encanto personal del guía lo que acerca esa presentación del patrimonio a los postulados de la interpretación: inspirando al público, invitándolo a que utilice sus sentidos, llegando a sus vísceras, y, quizá lo más importante, entregándole una frase que poder recordar.

Miguel Delibes de Castro (ex Director de la Estación Biológica de Doñana) comenta -en el prólogo del Libro Guía práctica para la Interpretación del patrimonio, del que soy autor- que la misión que él ve a los guías intérpretes es la de enamorar a los visitantes: "Descubrí, con sorpresa, que para entusiasmar a la gente no eran imprescindibles el calamón o la cerceta pardilla. Se la podía enamorar con el murmullo del viento". Y los/nos tilda, cariñosamente, de "alcahuetes y amables celestinas ocupadas en descubrir al visitante los más secretos atractivos, las más disimuladas virtudes, del espacio -parque natural, conjunto histórico, ecomuseo- que interpretan".

Lamentablemente, esos casos son contados, y la realidad es que en España somos muy pocos los que intentamos aplicar y divulgar la interpretación. Y no porque sea un misterio de tipo sectario, o una disciplina llena de complejidades. No, la interpretación es muy simple. El principal problema estriba, creo, en la falta de textos en idiomas del Estado Español, o en la escasa distribución de los trabajos existentes.

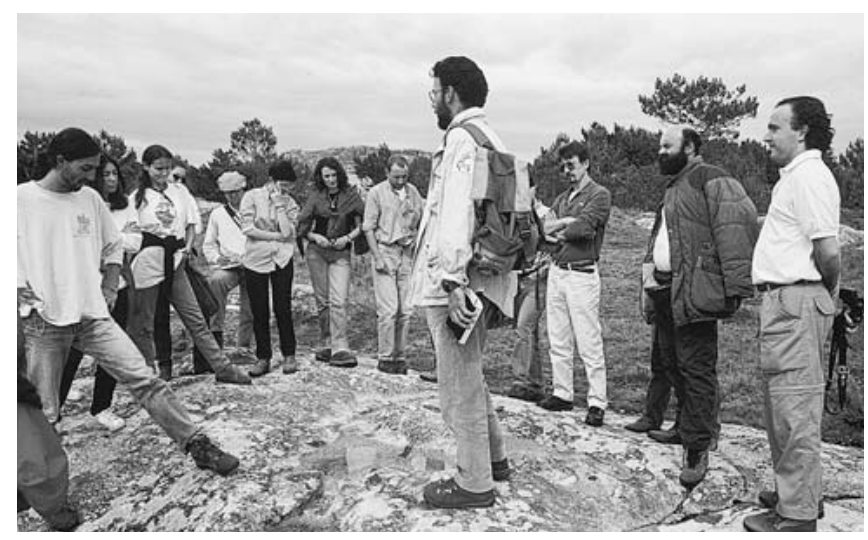

\section{Antes de interpretar hay que planificar}

Hasta aquí no he mencionado cómo hacer interpretación. Y, aun a riesgo de entrar en detalles, creo necesario y útil tocar este aspecto, pues me parece fundamental para establecer un "a qué nos referimos cuando hablamos de interpretación".

La interpretación es un proceso de comunicación que consta de varios elementos o momentos de acción:

a) Diagnóstico de una realidad: ¿hace falta interpretación? ¿para qué? ¿en qué medida mejorará la gestión del conjunto histórico o del paraje natural?

b) Planificación interpretativa: un proceso racional de formulación de objetivos, análisis del recurso y sus potencialidades (y limitaciones), análisis de los virtuales usuarios, definición de los mensajes a transmitir, elección de los medios de interpretación y definición de los equipamientos y servicios interpretativos necesarios, recomendaciones para la ejecución de los programas (personal, obras), y sugerencias para evaluar la efectividad de la intervención. El resultado de este proceso es un Plan de Interpretación.

c) Diseño específico de medios, equipamientos y programas: proceso creativo, realizado por especialistas en la materia, después de contar con un Plan de Interpretación y siguiendo las directrices indicadas en dicho documento. 
d) Ejecución de las obras e implantación de los programas: según lo establecido en el Plan de Interpretación y en los Diseños Específicos, la interpretación se traduce en personal, materiales y programas.

e) Presentación del patrimonio al visitante: "antepenúltima" acción que llena de sentido todo el esfuerzo anterior, esfuerzo necesario porque sin planificación interpretativa se cae irremediablemente en la improvisación, descoordinación y despilfarro de fondos.

f) Evaluación: se evalúa según lo recomendado en el Plan, o aplicando las estrategias de evaluación (rutinaria) que el propio personal del servicio de interpretación del lugar considere oportunas. Hay métodos para evaluar la interpretación, algunos prestados de otras disciplinas.

g) Retroacción, retroalimentación o feedback: es decir, la incorporación a los programas de los resultados y las evidencias surgidas de la evaluación. Todo el sistema tiene que alimentarse del producto de su propio análisis para mejorar la atención al público.

\section{Los trucos por aplicar son simples}

He mencionado que la interpretación requiere la aplicación de ciertas técnicas, sea en un museo cerrado o al descubierto en un parque natural. Esas técnicas son un recetario útil, pero completamente estériles si no se acompañan del toque personal de los planificadores, los diseñadores o los guías. Es preciso conocer, además, a qué tipo de público irá dirigida la interpretación, para afinar el mensaje y elegir la metodología que más les convenga a esos usuarios. Veamos ahora algunos de esos trucos, también a la luz del comentario anterior: "a qué nos referimos cuando hablamos de interpretación".

\section{A. Para el diseño del mensaje interpretativo:}

- Permítanme antes un inciso: nunca se debería usar la palabra interpretación ante el público. Al público no le dice nada, e incluso puede llegar a confundirlo; dejémosla como una palabrota para su uso por los técnicos. En consecuencia, la denominación centro de interpretación habría que erradicarla, al menos paulatinamente. El público se sentirá más aludido si se le presenta un equipamiento como museo, centro de información o centro de visitantes.

- Plantear objetivos específicos en cada programa, en tres aspectos:

I. Para el conocimiento: ¿qué queremos que la gente sepa?
Ejemplo: "Que el 80\% de los visitantes sea capaz de comentar que los factores que influyeron en la colonización de este territorio fueron el agua y los recursos mineros".

2. Para la afectividad: ¿qué queremos que la gente sienta?

Ejemplo: "Que la mayoría de la gente sonría tras la lectura del texto en los carteles".

3. Para las actitudes/comportamientos: ¿qué queremos que la gente haga (o no haga)?

Ejemplo: "Que todos los visitantes se comporten de forma respetuosa con el entorno, y sigan las indicaciones entregadas en el folleto".

Este planteamiento de objetivos contribuye bastante a orientar los esfuerzos de interpretación, y se puede aplicar a pequeña escala, por ejemplo en cada parada de un recorrido o en cada stand de exhibición; o a una escala mayor, como a toda una sala con exhibiciones/exposiciones o para todo un itinerario por el casco antiguo de un pueblo.

- Es conveniente definir una frase que queramos que el público recuerde. A este proceso se le denomina interpretación temática, y el tema tiene que contener todos los ingredientes de una oración (sujeto, predicado y complementos). Así se prepara el tema:

Por ejemplo:

I. ¿Qué queremos explicar? "Queremos explicar las rocas calizas".

2. Más concretamente ¿qué de las rocas calizas? "Queremos explicar el origen de la roca caliza".

3. Entonces, ¿qué queremos que la gente sepa? (o qué le diremos al visitante, en definitiva) Al visitante le diremos que "La roca caliza se origina en el fondo del mar".

Este tipo de frase representa el concepto de tema interpretativo, que luego se desarrolla con más explicaciones que giran en torno a él: "La caliza se formó por el depósito de las conchas y caparazones de animales marinos hace más de cien millones de años. Ahora forma montañas en algunas regiones". Esta explicación la puede dar un guía (o preguntárselo al público) o bien puede aparecer como texto en los carteles de un itinerario o en una exhibición de un centro.

- Ayuda bastante el utilizar la frase-tema como título de las presentaciones, o en los titulares de las exhibiciones, en los encabezados de los folletos, carteles, etc. Así, quien no lea la letra pequeña tendrá ya una información, una noticia (esta acepción de la palabra tema es como el titular de un periódico). Incluso puede estimular a seguir leyendo.

No hay nada más tedioso e inútil en una sala de museo o de un centro de visitantes que leer titulares como estos: La Fauna, La Geología, Calcolítico, Orogenia Alpina, Usos y Costumbres... en lugar de leer, por ejemplo (extraídos del Plan de Interpre- 
tación para el Futuro Parque Natural del Delta del Llobregat):

Los asentamientos humanos en el Delta se encuentran alejados de la costa

El ruido de los aviones depende de la tecnología de los motores y de la aceleración que impriman los pilotos

Los cultivos son una transición hacia el medio natural

Los humedales del Delta sirven a las aves como un puente entre otras zonas húmedas de Cataluña

\section{- Más con respecto al mensaje:}

- El público responde mejor cuando percibe que el "tono" del mensaje es como si lo hubiese preparado un vecino o un amigo.

- Es conveniente aludir al receptor (lector, oyente) y a algún aspecto de su personalidad.

- Hay que usar un lenguaje sencillo, comprensible por la audiencia. En los programas autoguiados se debe elegir cuidadosamente el nivel máximo de complejidad; normalmente se aconseja no superar el equivalente a segundo de E.S.O.

- La utilización de preguntas (sin abusar de esta estrategia) estimula y motiva al visitante. Las respuestas las debe proporcionar él, o las debe encontrar sin dificultad.

- En el mensaje, sea el comentario de un guía o el texto de un folleto, hay que incluir invitaciones a hacer algo y a utilizar los sentidos.

- Es importante tener presente que un mensaje interpretativo sólo puede ser un simple poema. No se trata de describir fenómenos o explicar objetos en todas las ocasiones.

- La parte final del programa debe retomar el tema, esa frase que se ha reiterado y desarrollado con ideas complementarias. Aquí se concluye.

\section{B. Para las exhibiciones en museos y centros de visitantes:}

- Las exhibiciones más simples son las más efectivas. Muchas veces la espectacularidad puede enmascarar al mensaje.

- Hay que tener en cuenta que el público empleará como promedio sólo un minuto frente a cada stand o unidad de exhibición, por tanto, el mensaje tiene que poder ser captado con rapidez. Tenemos que atraer la atención del visitante, pero luego hay que lograr mantenerla para que le dé tiempo a captar todo el mensaje (o los niveles de lectura que él decida).

- Si la exhibición pretende ser interpretativa, ha de tener volúmenes, contrastes, cierto grado de dinamismo y partes que se puedan manipular (cuando sea pertinente). El público debe poder interactuar física y/o intelectualmente con la exhibición. Y si está bien concebida, no hará falta que un guía la explique.
- La sala en que se encuentran las exhibiciones debería tener un nombre que emplee el concepto de frase-tema, explicado anteriormente.

- Cada stand debería desarrollar el mensaje con temas y subtemas, es decir, en los títulos y en sus correspondientes subtítulos el público tendría que obtener una información, una "noticia".

- Cada exhibición requiere una iluminación específica, que no interfiera con las luces del resto de la sala. Hay que evitar, también, los reflejos en los cristales o en las superficies reflectantes.

- El público es libre para elegir el recorrido a seguir, por lo tanto, no deberíamos supeditar la captación del mensaje a una secuencia determinada. La secuencia y el sentido la podemos sugerir, pero siempre será el propio visitante quien decida qué ver, cuánto ver/atender, y por dónde. (Recordemos que este tipo de comunicación no está destinado, en principio, a grupos escolares, sino al público general en su tiempo de ocio)

- En los centros de visitantes la interpretación en interiores, normalmente, no utiliza objetos reales. Se suelen exponer "representaciones" de la realidad; por este motivo, la interpretación debería posibilitar un contacto con el objeto real afuera, en el entorno del parque o del sitio histórico. La oportunidad de que el visitante tenga ese contacto con el objeto real es lo que da sentido a la interpretación del patrimonio.
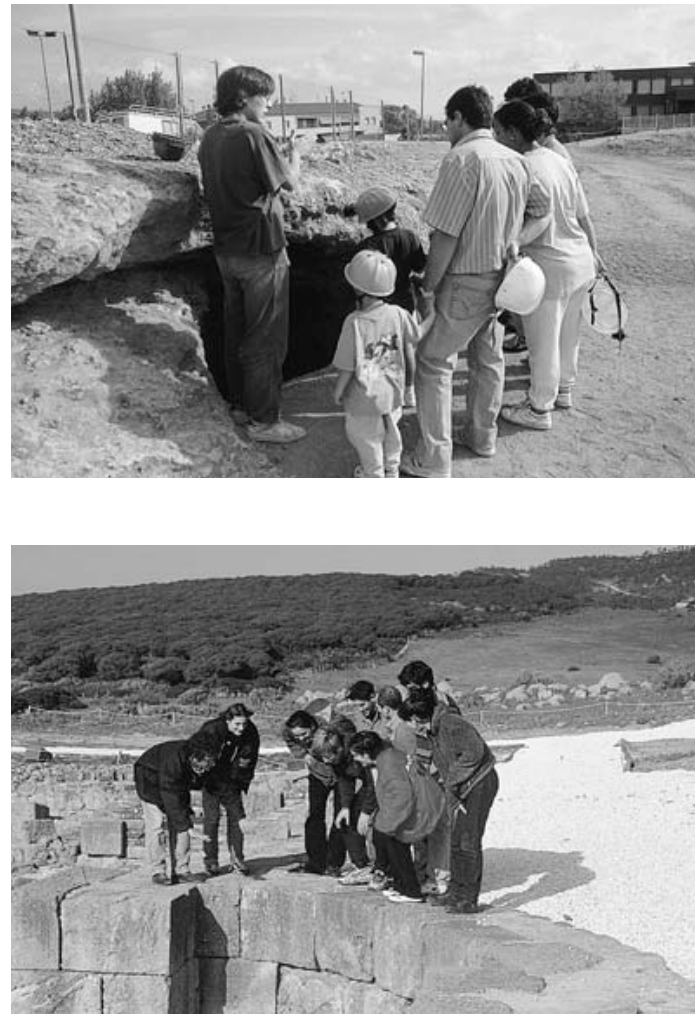

El caso de los museos es diferente, porque sí es probable que tengan más objetos originales, $y$, dependiendo del tipo de museo que se trate, habrá que aclararle al visitante cuál es el contexto (espacial, temporal, funcional) de las piezas expuestas.

C. Para los carteles (de paisaje, de sitio, de itinerarios, de parques urbanos)

Me voy a referir a carteles pequeños, de aproximadamente $40 \times 60 \mathrm{~cm}$, o más alargados, de $40 \times 120$ $\mathrm{cm}$. Los carteles o paneles más grandes entran en la categoría de "exhibiciones de exterior"; son los que 
suelen tener un tejadito y sirven para dar información. Poner interpretación en este tipo de soporte -con mucha superficie- es un poco más complicado, pero no imposible.

- Es totalmente imprescindible que estén integrados en el entorno, utilizando materiales locales y, a ser posible, relacionados con las cuestiones tratadas. Por ejemplo, soportes de piedra en sitios en los cuales predomine un determinado tipo de roca, o de cerámica si es relevante al contexto histórico.

- Los carteles rectangulares en horizontal son más agradables que los verticales o los cuadrados.

- Es aconsejable utilizar títulos del tipo frase-tema, y luego desarrollarlos en el resto del texto.

- El texto base deberá tener entre 90 a 100 palabras, y su estilo será directo e inspirador.

- Las ilustraciones que acompañen al texto tienen que ser pertinentes $y$, aunque generalmente se utilizan como simple decorado, las puede haber de tipo descriptivo. Las ilustraciones que describen no deben restarle la capacidad de "inspirar" al resto del cartel. No es obligado que haya ilustraciones.

- Si el cartel está instalado en exteriores, con buena insolación, es aconsejable que el fondo sea de un color oscuro y el texto e ilustraciones estén en un color claro, que contraste bien. Por el contrario, si el cartel está en sitios de umbría o con insuficiente entrada de luz (bosques, interior de recintos industriales, etc.), el fondo ha de ser de color claro y el texto e ilustraciones oscuros.

\section{Para otros medios de interpretación, las recomendaciones pueden ser muy parecidas}

- Audiovisuales con argumento (vídeo, diapositivas): duración de diez a quince minutos, de alta calidad artística, impactantes, y con comentarios que no saturen al público. Algunos pueden tener sólo música.

- Sistemas de audio (cassette transportable, teléfonos y postes de escucha): tienen que regirse por unas reglas similares a las de la persona-guía.

- Teatro, animación, fiestas, cuentacuentos, marionetas, charlas y demostraciones. Son posibilidades poco utilizadas, pero todas ellas poseen la mayor de las ventajas en interpretación: son ejecutadas por personas, el mejor sistema conocido para interpretar el patrimonio.

La consideración de éstos y otros aspectos, muy simples, hará que una presentación del patrimonio al público sea interpretativa. Y como se habrá podido apreciar, la interpretación hay que realizarla -casi- más en función del visitante que del patrimonio que se le quiere presentar. La interpretación es una estrategia de intervención social para conseguir un entendimiento, unas actitudes y un aprecio que, a la postre, revertirán en una mejor conservación del medio biofísico, social, e histórico cultural que consideramos como patrimonio.

\section{Hay antecedentes para un futuro esperanzador}

Mi experiencia y los múltiples documentos consultados, me impulsaron hace unos años a construir lo que denomino de forma coloquial como "la gran chuleta de la interpretación":

La interpretación tiene que:

- ser considerada como un eficaz instrumento de gestión

- ir dirigida al visitante del patrimonio (público general, incluidos los discapacitados)

- ser una actividad libre y voluntaria

- tener en cuenta el contexto recreativo en que se encuentra el visitante (vacaciones, días libres, etc.)

- ser inspiradora, que llegue al espíritu de los individuos

- estimular el uso de los sentidos

- ser motivadora y provocativa

- ser sugerente y persuasiva

- estimular la participación activa

- orientar e informar acerca de hechos concretos

- estimular el sentido crítico

- entregar un mensaje claro

- entregar un mensaje breve

- revelar significados e interrelaciones

- contribuir a la concienciación ciudadana

- contar con la presencia del objeto real

- recaer en lo posible en actividades personalizadas (con un guía)

- mantener como meta la conservación del patrimonio que es objeto de la interpretación

Quisiera poner cierto énfasis en la simpleza de la interpretación, y recordar la cita de Delibes: "hay que enamorar al visitante..." conseguir que se enamore del lugar que ha visitado. Porque lo habrá conocido, comprendido y valorado. Es posible que a través de la interpretación el visitante haya entendido qué sentido tiene para él ese lugar, cómo puede afectar a su vida la existencia de unos restos arqueológicos, o unos paisajes que otros humanos han modelado a través de siglos.

La interpretación es tan simple que, a veces, el puro sentido común puede dictar los pasos a seguir. Sin embargo, la disciplina posee un amplio acervo de conocimientos. Hay metodologías y personal técnico para aplicarlas. 
Por otra parte, la interpretación no tiene por qué traducirse en costosas inversiones. Si se cuenta con un especialista (desde la planificación), el coste de las inversiones puede ser significativamente menor que contratar directamente a una empresa que monta exposiciones. Más tarde pueden actuar todo tipo de proveedores de servicios concretos (audiovisuales, cartelería, senderos, exposiciones, impresos, etc.), pero supervisados por el técnico en interpretación.

No vayamos tampoco a inventar la pólvora. No exagero si digo que debe haber cientos de tesis doctorales relacionadas con la interpretación... pero todas en inglés, y, seguramente, circulando en esferas restringidas. Además, en los Estados Unidos y Canadá hay más de un centenar de instituciones dedicadas a dar formación en este campo: institutos, academias, facultades universitarias, museos, centros de investigación de parques nacionales, etc. En el Reino Unido hay otras tantas. En España se prepara un curso de posgrado en la Universidad de las Islas Baleares... Y con muchos esfuerzos se está dando forma a la Asociación para la Interpretación del Patrimonio, uno de cuyos fines es también promover la formación.

En cuanto a la documentación corriente, existen revistas especializadas editadas por diversas asociaciones de interpretación. Actualmente, incluso, el Journal of Interpretation está siendo traducido al castellano por la National Association of Interpretation.

Los intentos desde hace décadas de aplicar la interpretación en parques nacionales y naturales, lamentablemente, no han cuajado, por burocracia, ignorancia e intervenciones desafortunadas que han desvirtuado el sentido de esta tarea. Ahora tenemos una gran oportunidad: reintentar la interpretación, esta vez desde el ámbito de los espacios de patrimonio histórico, y sentar mejores precedentes.

\section{Bibliografía}

ALDRIDGE, DON. 1973. Mejora de la Interpretación de los Parques y la Comunicación con el Público. UICN (ed.), Segunda Conferencia Mundial sobre Parques Nacionales; Yellowstone y Grand Teton, EE.UU., I8-27 septiembre de 1972. Informe No. 25.

AYUNTAMIENTO DEL PRAT DE LLOBREGAT. 1998. Plan de Interpretación para el Futuro Parque Natural del Delta del Llobregat. Documento interno.

EDWARDS, R. YORKE. 1976. Interpretation: What Should it Be? Journal of Interpretation I (I). USA.

LUSTIG, LOREN W. 1982. The Use of Interpretation to Reduce Vandalism and Maintenance Costs: an Interpreter's In-Field Formula. Journal of Interpretation 7(2): 19-29. USA.

MEREDITH, JOICE E.; GARY W. MULLINS; Y ROSANNE W. FORTNER. 1995. Interpretation and the Affective Learning Domain. Legacy 6(4):24-31. USA.

MORALES, JORGE F. 1989. Un Recorrido por la Interpretación. En: Informe del Taller Internacional sobre Interpretación Ambiental en Áreas Silvestres Protegidas, Parque Nacional Puyehue, Osorno, Chile, 6 - 12 de diciembre de 1988. Oficina Regional de la FAO para América Latina y el Caribe, RLAC/89/2I - FOR - 29.
MORALES, JORGE F. 1994. ¿Centros de Interpretación? Carpeta Informativa del CENEAM (Centro Nacional de Educación Ambiental), ICONA. "Firma del Mes", octubre de 1994.

MORALES, JORGE F. 1997. Environmental, Historical, Cultural, Natural Interpretation: A Spanish View on Heritage Interpretation. Legacy 8(5): 10. USA.

PEART, BOB. 1977. Definition of Interpretation. Paper at: Association of Interpreters Naturalists Workshop, Texas A \& M University, April 1977.

RIDEUT-CIVITARESE, SANDRA; MICHEL H. LEGG; Y DAVID M. ZUEFLE. 1997. More Thoughts on the Differences Betwen Environmental Interpretation and Environmental Education. Legacy 8(6): 10,28-29. USA.

RISK, PAUL H. 1982. The Interpretive Talk. En: G. Sharpe (ed.), Interpreting the Environment, Wiley \& Sons, Inc., London.

TILDEN, FREEMAN. 1957. Interpreting Our Heritage. The University of North Carolina Press, Chapel Hill.

TRAGSA. 1995. Proyecto de Avance de la Interpretación y Señalización para la Reserva Natural de las Marismas de Santoña y Noja, Cantabria. Documento elaborado por TRAGSA para el Instituto Nacional para la Conservación de la Naturaleza (ICONA). 